\title{
Pollution Free Dyeing on Cotton Fabric Extracted from Swietenia macrophylla and Musa Acuminata as Unpolluted Dyes and Citrus. Limon ( $L$.$) as$ Unpolluted Mordanting Agent
}

\author{
Anowar Hossain ${ }^{1 *}$, AKM Saiful Islam ${ }^{1}$ and Ashis Kumar Samanta ${ }^{2}$ \\ ${ }^{1}$ Department of Textile Engineering, City University, Dhaka, Bangladesh \\ ${ }^{2}$ Department of Jute and Fibre Technology, University of Calcutta, India \\ *Corresponding author: Anowar Hossain, Department of Textile Engineering, City University, Dhaka, Bangladesh
}

submission: 海眥 May 03, 2018; Published: 眥 June 19, 2018

\begin{abstract}
Present research on pollution free dyeing and mordanting is indicated as a creative innovation of textile coloration on cotton fabric in which natural dyes were extracted from Swietenia macrophylla (Mahogany leaf) and Musa acuminata (Green Banana Pill) as an unpolluted dyes and Citrus. limon (L.) juice was applied as an unpolluted natural mordanting agent. There is no synthetic chemical was used during the whole progression in dyes extraction process and dyeing method. Both the treated and untreated fabric samples were tested for their dyeing performance in terms of color strength, K/S value and color fastness properties like color fastness to washing, rubbing and light. Higher K/S value of lemon mordanted sample was investigated by analysis of spectrophotometer for both dyeing with mahogany and green banana pill. Color fastness to washing and rubbing had been found moderately good for both dyeing with mahogany leaves and green banana pill with lemon mordanting. Moderately good color fastness to light had been found for dyeing with only mahogany leaves and green banana pill but improved light fastness was found for green banana pill with lemon mordanting. As per visual appearance, dyed fabric with green banana pill and lemon mordanting was found very even distribution of color on the surface of cotton fabric. An exceptionally attractive soft hand fell and color shading outcome was observed for dyeing with green banana pill comparing to mahogany leaves without having any additional application of synthetic softner which is the demand of both local and foreign customers in clothing industries.
\end{abstract}

Keywords: Natural dyeing; Natural mordanting; Mahogany leaf; Green banana pill; Lemon

\section{Introduction}

Textile materials are colored for value addition, looks and fulfilling the desires of customers. Textile industries are highly concentrated to synthetic dyes due to having availability as well as desired shade maching capability, but synthetic dyes are highly polluting the environment which has become an alarming issue for the scientist concerns of textile and environment engineering. So, natural dyes can be a permanent replacement for the development of pollution free concepts of dyeing and finishing. Anciently, this purpose of coloring textile was initiated using natural source, until synthetic dyes were invented in 1856. Natural dyes are dyes or colorants that are derived from plants, animals, insects and minerals. Most of natural dyes are prepared from dye bearing plants - leaves, stem, barks, seeds, flowers, roots etc. There are many trees in the Northeast Bangladesh, which can be used as the major sources of natural dyes. For example, Swietenia macrophylla, Diospyros malabarica, Musa acuminata etc. Natural dye has a great demand in the international market. Dyeing extracted from Swietenia macrophylla (Mahogany leaf) and Musa acuminata (Green banana pill) are not available in the brief study of literature review.
Due to the current economic and environmental consciousness, research in this front should be titled towards the use of natural dyes for dyeing textile materials. Today, people around the globe are rediscovering color through the use of renewable and non-toxic natural sources. For successful commercial use of natural dyes for any particular fibers, the appropriate scientific standardized techniques/procedures are to be derived. Thus, relevant scientific studies and its output on standardization of dyeing methods, dyeing process variables, dyeing kinetics and test of compatibility of selective natural dyes and natural mordant have become very important. Lemon juice, Tamarind is also selected as the most important natural mordant to standardize the dyeing effect.

Growing consciousness for eco-friendly textile products has caused more interest on cotton fibre based natural dyeing and finishing. Productions of synthetic dyes are dependent on the petrochemical source and some of the synthetic dyes contain toxic/ carcinogenic amines and are not eco-friendly. Contrary to this, most of the natural dyes as well as natural finish with few exceptions 
are based on vegetable/animal origin and are renewable, biodegradable, energy-efficient and eco-friendly [1,2]. Single and binary mixtures of aqueous extracts of red sandalwood (RSW) with aqueous extract of other natural dyes like manjistha (MJ), jackfruit wood (JFW), marigold (MG), sappan wood (SW) and babool (BL) in different proportions are applied on bleached jute fabric for its dyeing after double pre-mordanted with myrobolan and aluminium sulphate applied in sequence under optimised conditions of mordanting with effects of use of different proportions of binary mixture of selective natural dyes on colour strength and other colour where good fastness properties were observed [3]. Bleached cotton fabric (after sequential pre-mordanting with myrobolan and then with aluminum sulfate applied in sequence) had been dyed with a pre-fixed concentration of purified binary mixtures of jackfruit wood (JFW) and other natural dyes, like manjistha (MJ), red sandalwood (RSW), mariegold (MG), sappan wood (SW) and babool (BL) in different proportions to obtain a variety of compound shades wherever color strength (K/S values), washing and color fastness properties were improved [4]. Natural extracted dyes, manjistha was applied on cotton fabric and observed the improvement of wash and light fastness properties [5]. Myobolan (Harda) and metallic salts (Potash alum and aluminium sulphate) as mordants and aqueous extract of Tesu (Palash flower petals) as dyeing agent was used and found improved wash and light fatness [6]. Myrobolan (harda) and other mordants (metallic salts) followed by dyeing with aqueous extract of Jackfruit and found good color fastness properties [7].

Yasashri Ranganath studied that Bark of Swietenia macrophylla (Mahogany) is a valuable natural dye source for textile. 1\% alkaline solution was used for the extraction of the dye from the finely crushed bark at 90 Celcius. Optimum dye extraction was obtained at 2 hours and optimum on weight goods (owg) ratio for extraction was 1:6. Usually a salt of $\mathrm{Al}, \mathrm{Fe}, \mathrm{Cr}, \mathrm{Cu}$, or $\mathrm{Ti}$ has to be used as the mordant to enhance the affinity of the nature dye to the fabric. In order to test the best mordant for this dye, $4 \%$ on weigh fiber (owf) solution of $\mathrm{Al} 2\left(\mathrm{SO}_{4}\right)_{3}, \mathrm{MgCl}_{2}, \mathrm{FeSO}_{4}$ were applied. $\mathrm{MgCl}_{2}$ showed the best uniform dyeing, thus it was used as the optimized mordant for dyeing experiments. Adsorption of extracted mahogany dye to the cotton fabric and adsorption capacities are significantly affected by $\mathrm{pH}$, initial dye concentration and temperature of the dye bath. In the current study the dye bath was maintained at $\mathrm{pH}=10$ and temperature at 90 Celcius for 2 hours and 1:50 metal to liquor ratio of the mordent was used. Amount of dye adsorption reached to the saturation when dye concentration was at 200ppm. Dye adsorption data at 90 Celcius were analyzed using Langmuir and Frendlich isotherms and CIELab colour values was measured [8].

Rakesh Kumar \& YC [9] Tripathi studied that atharveda carries description of natural dyes. Bhrigu Samhita was written about using natural dyes. Colour formed a basis to the various economic activities. Kautilya's Arthasastra dating back to 298 BC bears account of durations (days) allowed for various types of colouration and wages to be provided to the then professional artisans. Archaeological evidences shows that the dyeing was a widespread industrial enterprise in Egypt, Indiana and Mesopotamia around third millennium BC. The art of dyeing was as old as human civilization. From the historical records it is learnt that natural colorants were available to people during Greco-Roman periods [9].

Prabhu \& Aniket [10] deliberated that natural dyes, which were pushed during the last sixty years into the background by synthetic dyes, are recently again becoming object of consumer interests. This is due to the awareness of possible risks during production of synthetic dyes which involve use of petrochemical based raw materials and the violent chemical reactions for their synthesis. The manufacture of such dyes is energy intensive with adverse impact on environment adding to its pollution. Many of these dyes, especially the azo - based ones, are found to be carcinogenic. In this background, a brief review of natural colourant from plant sources, their classification, chemical constituents responsible for producing different colours, its activities and effect of different mordants on the hue is discussed. Different classes of mordants employed for fixation of natural colouration on textiles substrated, its mechanism and plant sources are also discussed [10].

Narayana \& Gowda [11] studied that eco-friendly natural dye extracted from Swietenia mahogany leaves, has been used as ecofriendly dye to cotton and silk fabrics. The dyeing was carried out with and without the use of mordants and the fastness properties of the fabrics were determined. Colour values in terms of $\mathrm{K} / \mathrm{S}$ and $L^{*} a^{*} b^{*} C$ and $h$ colour coordinates were examined. A wide range of shades were obtained by using various mordants and mordanting techniques. Dye was tested for some eco-parameters using atomic absorption spectrophotometry and GC/MS. The effluent disposed at the end of the processing was also tested in some cases. The test results were compared with set standards to determine the eco-friendliness of natural dye, show that their concentrations are much below the stipulated limits [11].

Kumaresan [12] found that Fastness properties of the flower of Spathodea campanulata and Cordia sebestena dyed cotton fabric have been studied using different combination (1:3,1:1 and 3:1) of various mordants, such as myrobolan: nickel sulphate, myrobolan: aluminium sulphate, myrobolan: potassium dichromate, myrobolan: ferrous sulphate and myrobolan: stannous chloride. The wash, rubbing, light and perspiration fastness of the dyed samples have been evaluated. Comparing the fastness properties and colour strength of flower of Spathodea campanulata and Cordia sebestena dyed cotton by using combination of mordants. In the comparative study of fastness properties and colour strength of the dyed cotton samples Spathodea campanulata in simultaneous mordanting method with 1:3 mordant combinations gives better results than using flower of Cordia sebestena [12].

Ploysai Ohama, Nattida Tumpat confirmed that Natural dye extracted from Caesalpinia sappan linn was applied to a cotton fabric and silk yarn by dyeing process. The dyestuff component of Caesalpinia sappan linn. was extracted using water and ethanol. Analytical studies such as UV-VIS spectrophotometry and gravimetric analysis were performed on the extracts. Brazilein, the 
major dyestuff component of Caesalpinia sappan linn was confirmed in both aqueous and ethanolic extracts by UV-VIS spectrum. The color of each dyed material was investigated in terms of the CIELAB ( $\mathrm{L}^{*}, \mathrm{a}^{*}$ and $\mathrm{b}^{*}$ ) and $\mathrm{K} / \mathrm{S}$ values. Cotton fabric dyed without mordant had a shade of reddish-brown, while those post-mordanted with aluminum potassium sulfate, ferrous sulfate and copper sulfate produced a variety of wine red to dark purple color shades. Cotton fabric and silk yarn dyeing was studied using aluminum potassium sulfate as a mordant. The observed color strength was enhanced with increase in mordant concentration [13].

Kartick \& Basak S [14] studied that agro-waste, nanolignin, silk sericin and aloe vera have been successfully extracted and applied in textile substrates to protect its user from the harmful ultraviolet (UV) rays. The above natural ingredients and a few more from marigold, manjistha, annatto, neem, turmeric, sandalwood, tulasi, jasmine, lemon, lavender and sandalwood have also been explored for natural dyeing, UV protective, aroma and antimicrobial finishing of textile [14]. Sudipta \& Subhas [15] was investigated that screen printing on cotton fabric using Cochineal natural dye in the presence of stannous chloride as the mordant. It was found that, the dye recipe using 6\% Cochineal pigment in water-based solvent, where the fabric was soaked in the heated stannous chloride mordant for an hour and cured at $160{ }^{\circ} \mathrm{C}$ for $3 \mathrm{~min}$, produced the best screen print on $100 \%$ cotton fabric in terms of appearance and color wash fastness [15].

Mohammad \& Felix [16] studied on natural dyed samples and conducted with several tests like wash fastness, rubbing fastness, light fastness and $\mathrm{K} / \mathrm{S}$ value. Comparison also done among water extracted dyed samples and organic solvent (Methanol) extracted dyed samples and all the results came up with good results [16]. Jixian et al. [17] was found that the superior dyeing effect of cotton fabric was achieved by adjusting the dye bath $\mathrm{pH}$. When the $\mathrm{pH}$ was

Table 1: Materials used for experimental works. three, dyed cotton under $90{ }^{\circ} \mathrm{C}$ for 60 min exhibited the greatest color strength with good rubbing, washing and perspiration color fastness [17]. Jyoti \& Prerna [18] attempted made to extract natural dyes from a variety of plants sources (such as rhizomes of turmeric, Curcuma longa; fruits of harda, Terminalia chebula; petals of safflower, Carthamus tinctorius; roots of barberry, Berberis lycium etc.) using specific techniques. These dyes were tested for their dyeing potential on different textile materials (cotton, silk and wool). Dyeing was done using three different dyeing techniques (pre-, simultaneous- and post-mordanting) wherein different mordants such as alum, copper sulphate and ferrous sulphate etc., were used to fix dye on to the textile material. A rainbow of natural dyes was obtained with varied shades of each colour. Shade cards were prepared for each dye and the colour obtained varied depending on the type of the mordant applied and the mordanting technique used [18].

Smita \& Nabaneeta [19] reviewed of interest in the use of natural dye in textile colouring is due to the stringent environmental standard imposed by many European countries in response to the toxic and allergic reaction associated with synthetic dyes. Germany was the first to take initiative to put ban on numerous specific azodyes for their manufacturing and applications. Netherlands, India and some other countries also followed the ban. Varieties of colour, shades from vibrant jewel tones to dusky heathers and pastels can be obtain from different sources [19]. Anowar \& Samanta [20] was experimented and found that dyeing with green gaub fruit, color fastness to wash and rubbing=very excellent, color fastness to light=good and for dyeing with green tea leaf, color fastness to wash=very excellent, color fastness to rubbing=excellent, color fastness to light=good. An improved color strength, K/S value had been found for both dyeing with green gaub fruit and green tea leaf while mordanting was applied with green lemon juice [20] (Table 1).

\begin{tabular}{|c|c|c|}
\hline Sl. No & Materials Name & Source \\
\hline 1. & $\begin{array}{c}\text { Knitted Fabric: GSM 150 } \\
\text { (Scoured \& Bleached) }\end{array}$ & Apparel Village, khagan, Savar, Dhaka, Bangladesh \\
\hline 2. & Swietenia macrophylla (Mahogany leaf), as natural dyeing agent & From the Garden, Ashulia, Khagan, Savar, Dhaka, Bangladesh \\
\hline 3. & Musa acuminate (Green Banana Pill), as natural dyeing agent & Vegetable Garden Ashulia, Khagan, Savar, Dhaka, Bangladesh \\
\hline 4. & Lemon as natural mordanting agent & Vegetable Garden Ashulia, Khagan, Savar, Dhaka, Bangladesh \\
\hline 5. & Distilled Water & Mother Trade International Mirpur, Dhaka, Bangladesh \\
\hline
\end{tabular}

\section{Method Used for Experimental Works}

\section{Dyeing of cotton fabric with mahogany leaves and no mordanting in dye bath}

Extraction process of mahogany leaves: Collected fresh Mahogany leaf from garden and smashed it and weighted 2gm powder by electronic balance. After that we took 98cc water and heated up to $80{ }^{\circ} \mathrm{C}$ for $40 \mathrm{~min}$. Then we filtered the total solution of powder by very fine mesh fabric and got the dye solution.
Dyeing process: Dyed the specific fabric with $5 \mathrm{gm}$ weight in $70{ }^{\circ} \mathrm{C}$ for $30 \mathrm{~min}$ by keeping the material and liquor ratio: $1: 6$. Then we dyed the total fabric. Temperature checked by thermometer and finished with padding and drying method.

\section{Dyeing of cotton fabric with mahogany leaves and lemon mordanting in dye bath}

Green Lemon juice was extracted manually and lemon juice (15\% of total solution i.e mahogany leaf extraction) was added. 
After that we dyed the specific fabric with $5 \mathrm{gm}$ weight in $70{ }^{\circ} \mathrm{C}$ for $30 \mathrm{~min}$. Then we dyed the total fabric by keeping the material and liquor ratio: 1:6. Temperature checked by thermometer and finished with padding and drying method.

\section{Dyeing of cotton fabric with green banana pill and no mordanting in dye bath}

Green banana pill extraction process: First collected green banana from bazar and made into small split by knife and weighted $30 \mathrm{gm}$ by electronic balance. After that we took $70 \mathrm{cc}$ water and heated up to $80{ }^{\circ} \mathrm{C}$ for $40 \mathrm{~min}$. Then filtered the total solution of banana split and got the dye solution.

Dyeing process: Dyed the specific fabric with $5 \mathrm{gm}$ weight in $70{ }^{\circ} \mathrm{C}$ for $30 \mathrm{~min}$ by keeping material and liquor ratio: $1: 6$. Then dyed the total fabric. Temperature checked by thermometer and finished with padding and drying method.

\section{Dyeing of cotton fabric with green banana pill and lemon mordanting in dye bath}

Green Lemon juice was extracted manually and lemon juice (15\% of total solution i.e banana pill extraction) was added. After that we dyed the specific fabric with $5 \mathrm{gm}$ weight in $70^{\circ} \mathrm{C}$ for $30 \mathrm{~min}$ by keeping the liquor ratio: $1: 6$. Then dyed the total fabric in similar way. Temperature checked by thermometer and finished with padding and drying method.

\section{Methods used for different testing in research works}

Color fastness to wash: was tested ISO 105-A05, Textiles Tests for color fastness - Part A05: Instrumental assessment of change in color for determination of grey scale rating with Launder-o-Meter.

Color fastness to light: was tested by AATCC TM16 in Q-SUN XE-2 Xenon test chamber against blue wool standards (BS -1006B01-1978).

Color fastness to Rubbing: was tested ISO 105-X12:2001(E) which finger and force were used in the test. Whether dry or wet rubbing was performed along with the percentage of soak the numerical rating for staining for each test specimen. The staining of the cotton rubbing cloths with the grey scale for staining 4.4 under suitable illumination.

Color strength (K/S value): was measured by measuring surface reflectance value where Computer color measuring instrument (Macbeth 2020 plus spectrophotometer). Color strength of untreated and treated cotton fabric samples is measured from the reflectance value at maximum wave length from which surface color strength (K/S value) can be determined by kubelka- munk equation:

$$
\frac{K}{S_{\lambda \max }}=\frac{\left(1-R_{\lambda \max }\right)^{2}}{2 R_{\lambda \max }}=\alpha C_{D}
$$

Where, $\mathrm{K}=$ coefficient of absorption

$S=$ coefficient of scattering

$\mathrm{R} \lambda \max =$ reflectance of the substrate at maximum absorbance wavelength

$$
\mathrm{CD}=\text { concentration of dye }
$$

\section{Results \& Discussions}

Natural dyeing on cotton fabric extracted from Swietenia macrophylla (Mahogany leaf), Musa acuminata (Banana Pill) with natural mordanting agent wherever both the treated and untreated fabric samples were tested for their dyeing performance in terms of color fastness properties (color fastness to washing and rubbing, light fastness). Color fastness to wash and rubbing had been found moderately good for dyeing with mahogany and lemon juice but moderately good color fastness to light had been found for dyeing with only mahogany without lemon juice as well as color fastness to wash, color fastness to rubbing was found moderately good and color fastness to light had found excellent for dyeing with green banana pill and lemon juice in addition to very attractive soft hand fell was observed by the researcher which one was dyed with green banana pill (Table 2).

\begin{tabular}{|c|c|c|c|c|}
\hline \multirow{2}{*}{ Treatment } & \multirow{2}{*}{$\begin{array}{c}\text { Color Fastness } \\
\text { to Wash }\end{array}$} & \multirow{2}{*}{$\begin{array}{c}\text { Light } \\
\text { Fast- } \\
\text { ness }\end{array}$} & \multicolumn{2}{|c|}{$\begin{array}{c}\text { Color Fastness to } \\
\text { Rubbing }\end{array}$} \\
\hline & & & Dry & Wet \\
\hline Treated fabric with only Mahogany & 3 & 3 & 3 & 2 \\
\hline Treated fabric with Mahogany \& Lemon & 4 & 2 & 4 & 3 \\
\hline Treated fabric with Only Banana Pill & 3 & 2 & 3 & $2-3$ \\
\hline Treated fabric with Banana Pill \& Lemon & 4 & 3 & $4-5$ & 4 \\
\hline
\end{tabular}

Table 2: Assessments of color fastness parameters for dyeing with mahogany leaves and green banana pill.

\section{Color fastness to wash}

For Mahogany, the color fastness to wash tabulated and showed in graph that the mordanted sample showed better color fastness. It has been investigated that naturally mehgony has good color fastness due to its natural chemistry i.e presency of ferrous. For green banana pill, the color fastness to wash tabulated and showed in graph that the mordanted sample showed better color fastness. It has been investigated that naturally green banana pill has good color fastness due to its natural chemistry i.e presency of natural pigment (Figure 1) 


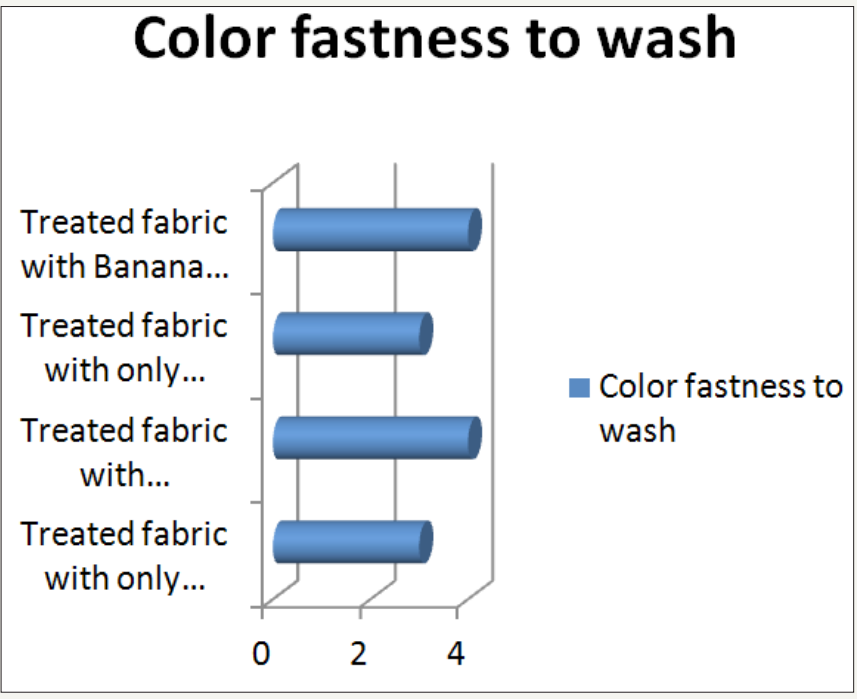

Figure 1: Color fastness to wash.

\section{Color fastness to light}

Exceptional result had been remarked as the graph showing that treated fabric with only mahogany have better light fastness comparing to mordanted sample. In the presence of citric acid, color is slightly faded due to having ferrous and other compositional contents in mahogany leaves. For banana pill, the colorfastness to light tabulated in table and graphical representation showed that the mordanted sample is better than un mordanted fabric, but treated fabric with only banana pill had found good color fastness to light (Figure 2).

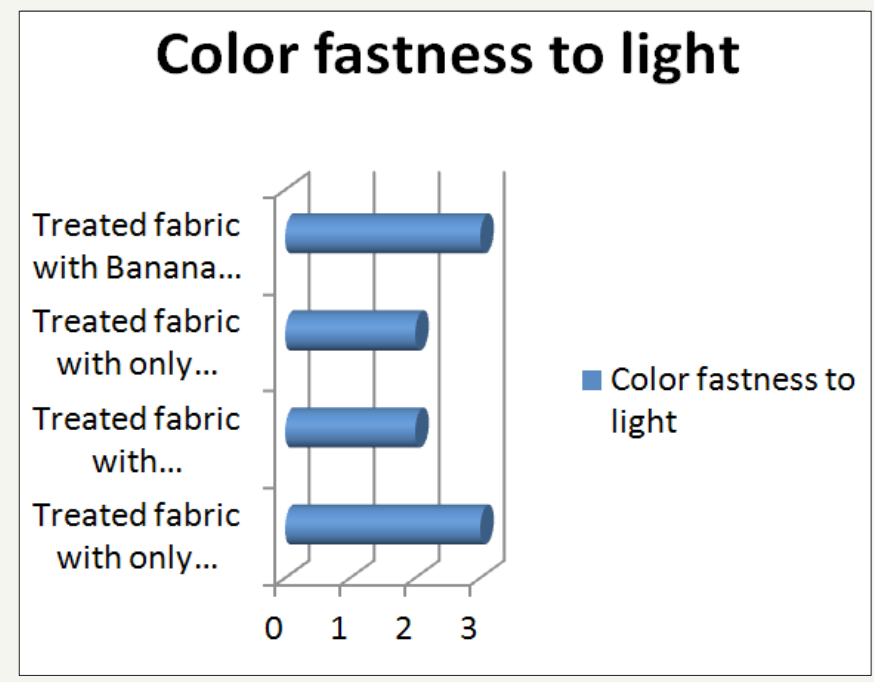

Figure 2: Color fastness to light.

\section{Color fastness to rubbing}

For both mehogany and banana pill, rubbing fastness from table and graph, it can be understood that the mordanted samples exhibited better rubbing fastness under dry and wet conditions. The mordanted samples had good fastness under both crocking conditions (Figure $3 \& 4$; Table 3 ).

Table 3: Comparison of K/S value between mahogany leaves and green banana pill dyed fabric.

\begin{tabular}{|c|c|c|}
\hline Sl. No & Treatments & K/S Value \\
\hline 1. & Untreated fabric & 0.122 \\
\hline 2. & Dyed fabric with Mahogany & 1.90 \\
\hline 3. & Dyed fabric with Mahogany and lemon as mordanting agent & 2.34 \\
\hline 4. & Dyed fabric with Green Banana Pill & 1.20 \\
\hline 5. & Dyed fabric with Green Banana Pill and lemon as mordanting agent & 1.60 \\
\hline
\end{tabular}




\section{Color fastness to rubbing (Dry)}

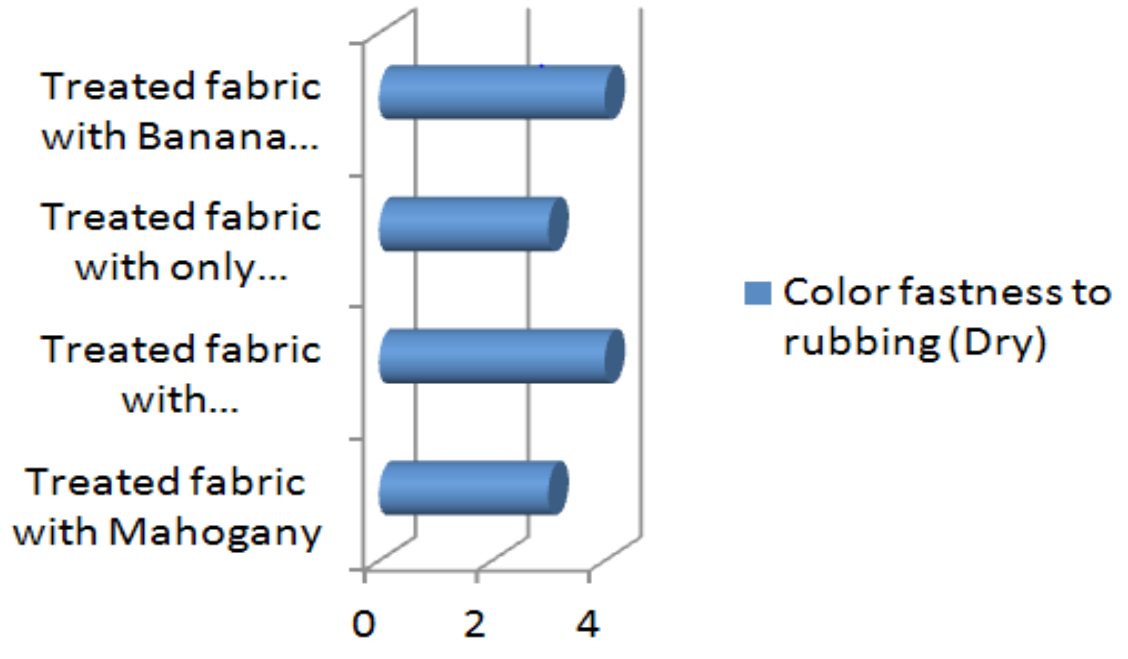

Figure 3: Color fastness to rubbing (dry).

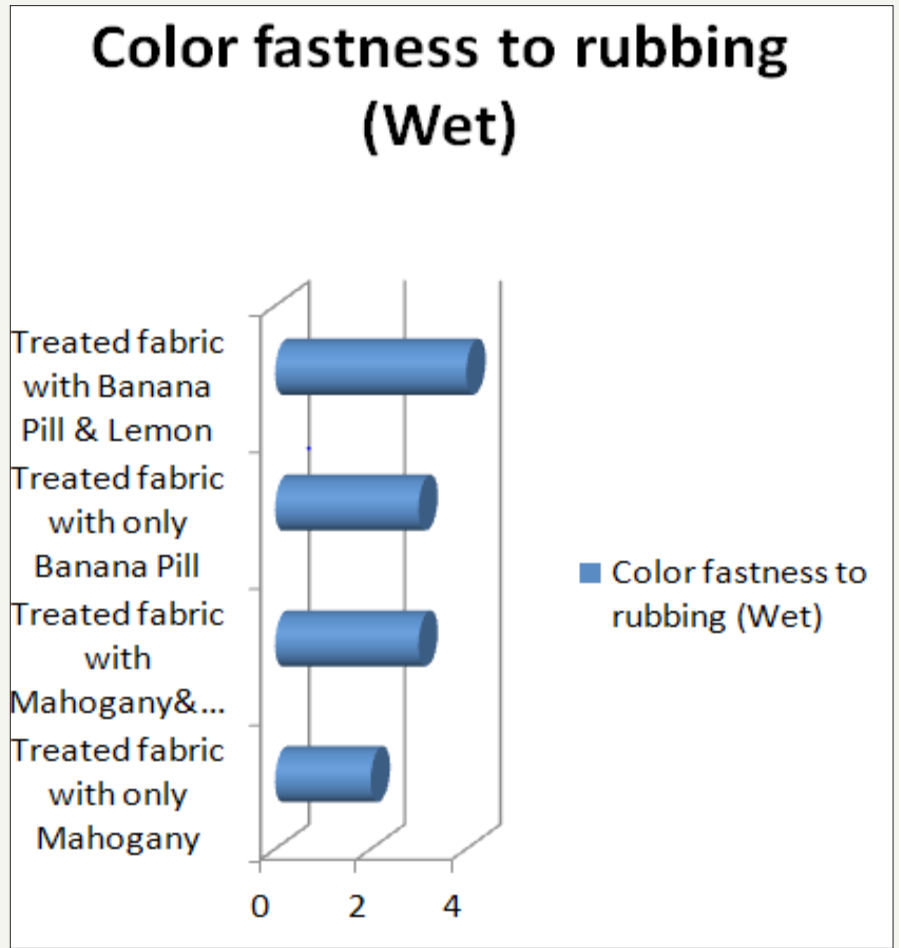

Figure 4: Color fastness to rubbing (wet).

\section{Color strength, K/S}

From graphical demonstration of color strength measurement, it has been clearly confirmed that $\mathrm{K} / \mathrm{S}$ value of mordanted sample was increased for both of dyeing with mahogany and green banana pill. As per compositional overview, Mahogany leaf contains
Ferrous which is responsible for making color and Banana pill has coloring pigment for making color which parameters are effecting to get higher $\mathrm{k} / \mathrm{s}$ value for both dyeing. It can be also noted that crosslinking in both dye bath reaction is increasing due to presency of citric acid in lemon (Figure 5 \& 6). 


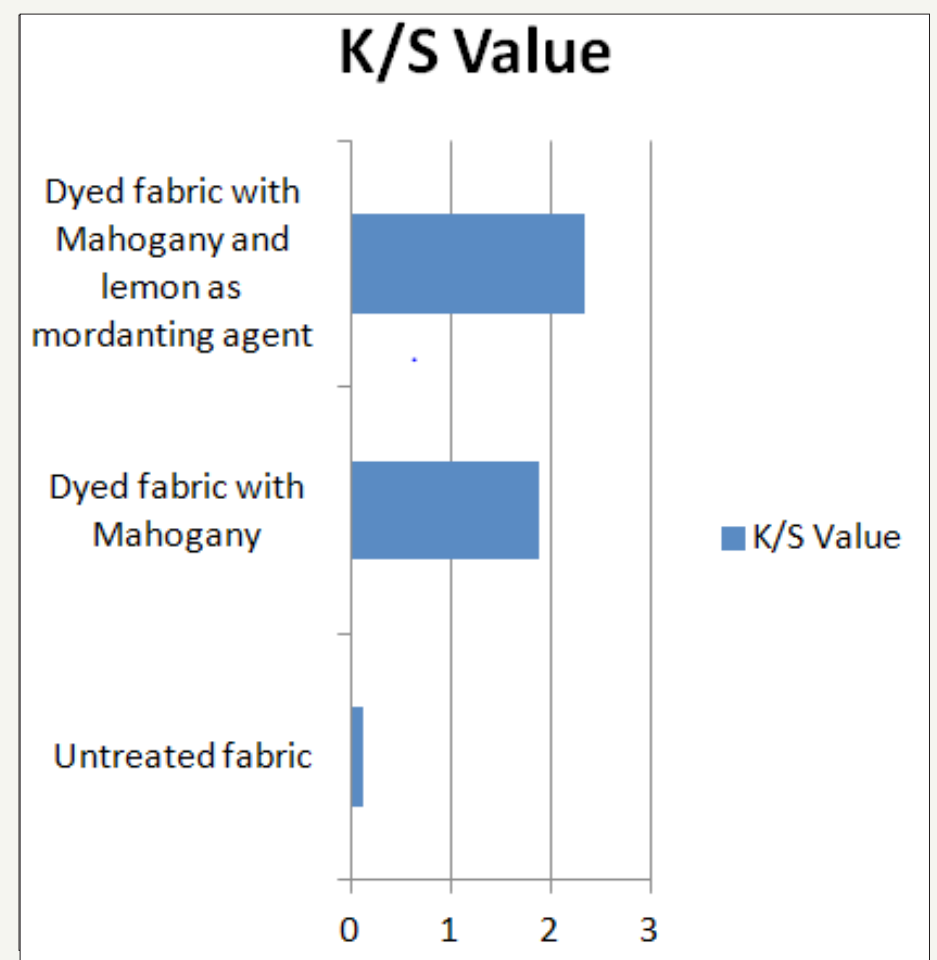

Figure 5: Color strength, K/S value of dyed fabric with mahogany leaves.

\section{K/S Value}

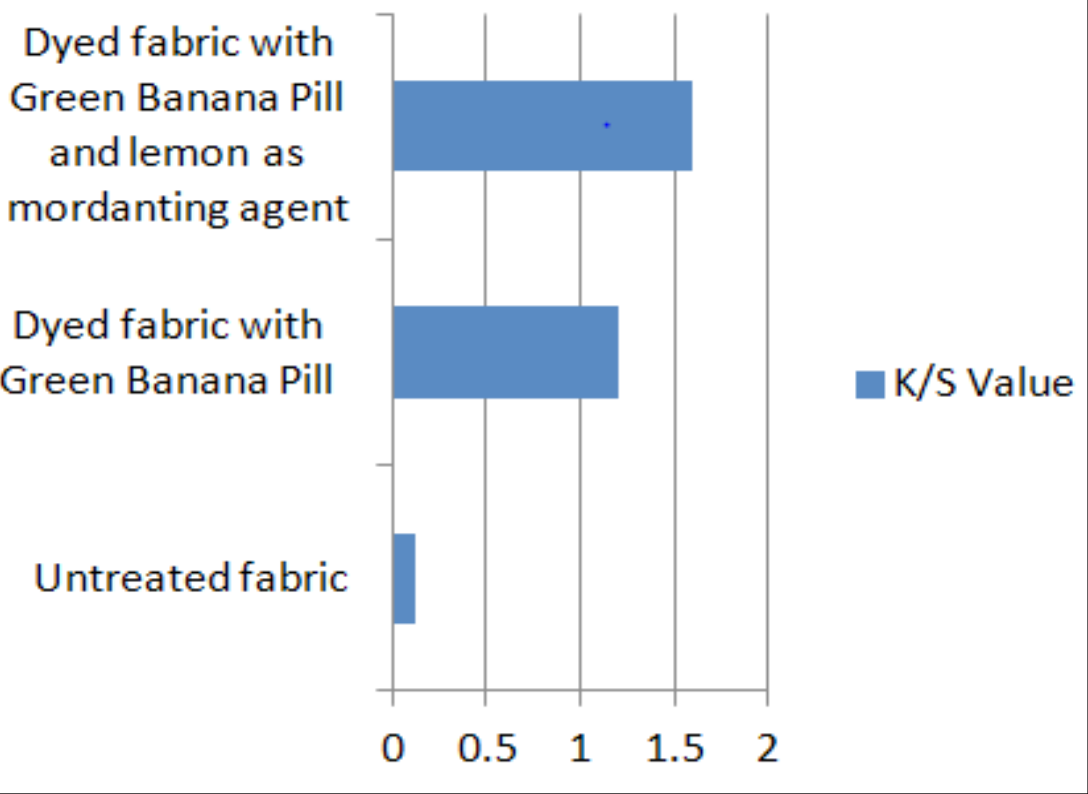

Figure 6: Color strength, K/S value of dyed fabric with green banana pill.

\section{Conclusion}

For both dyeing with mahogany leaves and green banana pill was found higher $\mathrm{k} / \mathrm{s}$ value with lemon mordanting and moderate to excellent color fastness to washing and rubbing. Color fastness to light was found good for dyeing with only mahogany and banana pill as well as improved color fastness to light was observed for green banana pill with lemon mordanted sample. Moderate to excellent fastness was found for rubbing, wash and light like color fastness to rubbing $>$ Color fastness to wash $>$ Color fastness to light. This new findings of present research can be considered for the practice of almost $100 \%$ ecofriendly dyeing of cotton fabric without having any 
negative impact on environment due to $0 \%$ application of synthetic dyes and mordanting. So this research work may be accepted by the scientist as presently environment pollution of textile dyeing and finishing has become the major thinking matter of both scientist concern of textile engineering and environmental engineering. Furthermore chemical structure analysis of all extracted solution of mahogany, green banana pill and lemon can be studied deeply and if it can be matched accurately the related study and research can be purely established in the field of natural dyeing considering more fastness and $\mathrm{K} / \mathrm{S}$ value which may be invented as ecofriendly dyeing of textile engineering. This research work can fulfill the versatile color demand as per customer discussed in literature review.

\section{References}

1. Samanta AK, Singhee D, Sethia M (2003) Application of single and mixture of selective natural dyes on cotton fabrics: A scientific approach. Colourage 50(10): 29-42.

2. Dedhia EM (1998) Natural dyes. Colourage p. 45.

3. Samanta AK, Priti A, Deepali S, Siddhartha D (2009) Application of single and mixtures of red sandalwood and other natural dyes for dyeing of jute fabric: studies on colour parameters/colour fastness and compatibility. The Journal of textile institute 100(7): 565-587.

4. Samanta AK (2009) Studies on color interaction parameters and color fastness properties for dyeing of cotton fabrics with binary mixtures of jackfruit wood and other natural dyes. Journal of natural fibre 6(2): 171190.

5. Samanta AK (2010) Effect of different mordants, extraction conditions and dyeing process variables on colour interaction parameters and colour fastness properties in dyeing of jute fabric with manjistha. A Natural Dye Journal of Institution of Engineers Textile Engg, pp. 7-15.

6. Samanta AK (2011) Dyeing of jute fabric with tesu extract: part 1-effects of different mordants and dyeing process variables. Indian Journal of Fibre and Textile Research 36: 63-73.

7. Samanta AK (2007) Dyeing of jute and cotton fabrics using Jackfruit wood extract: part 1-effects of mordanting and dyeing process variable on color yield and color fastness properties. Indian Journal of Fibre and Textile Research 32: 466-476.
8. Yasashri R (2017) Optimization of parameters for extraction of dye from swietenia macrophylla (mahogany) and adsorption isotherms on cotton fabric.

9. Rakesh K, YC. Training manual on extraction technology of natural dyes \& aroma therapy and cultivation value addition of medicinal plants. Natural dye from forest biomass.

10. Prabhu KH, Aniket SB (2012) Plant based natural dyes and mordnats: A Review. Department of Textile Chemical and Colour, Wool Research Association 2(6): 649-664.

11. Narayana VS, Ninge GKN (2015).

12. Kumaresan M (2015) Tamilnadu scholars research library der pharma chemica. Department of Chemistry, Erode Sengunthar Engineering College, Thudupathi, India, 7(4): 257-260.

13. Ploysai $O$ (2014) Nattida tumpat textile dyeing with natural dye from sappan tree (Caesalpinia sappan Linn.) extract. World Academy of Science, Engineering and Technology International Journal of Materials and Textile Engineering 8(5).

14. Kartick KS, Basakand S, Chattopadhyay (2016) Sustainable dyeing and finishing of textiles using natural ingredients and water-free technologies. Textiles and Clothing Sustainability, pp. 99-131.

15. Sudipta D \& Subhas G (2018) Evaluation of screen printing using cochineal natural dye. Trends in Textile Engineering and Fashion Technology.

16. Mohammad R, Felix Y T, Saifur R (2016) Eco-friendly dyeing of wool fabric using natural dye extracted from onion's outer shell by using water and organic solvents. International Research Journal of Engineering and Technology (IRJET) 3(9): 450-467.

17. Jixian G, Yanfei R, Ranran F, Zheng L, Jianfei Z (2017) pH-mediated antibacterial dyeing of cotton with prodigiosins nanomicelles produced by microbial fermentation. Polymers 9(10): 468.

18. Jyoti A, Prerna A, Gunjan G (2017) Rainbow of natural dyes on textiles using plants extracts: sustainable and eco-friendly processes. Green and Sustainable Chemistry 7: 35-47.

19. Smita B, Nabaneeta G, Kalita BB (2016) Natural dyes and its antimicrobial effect. International Journal of Engineering Trends and Technology 42(3): 103-105.

20. Anowar H, Samanta AK (2018) Green dyeing on cotton fabric demodulated from diospyros malabarica and camellia sinensis with green mordanting agent. Latest Trends in Textile and Fashion Designing 2(2): 1-8.
Creative Commons Attribution 4.0 International License

For possible submissions Click Here

\section{Submit Article}

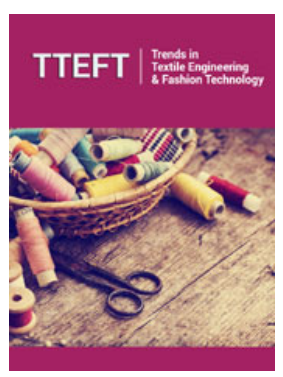

Trends in Textile Engineering \& Fashion Technology

\section{Benefits of Publishing with us}

- High-level peer review and editorial services

- Freely accessible online immediately upon publication

- Authors retain the copyright to their work

- Licensing it under a Creative Commons license

- Visibility through different online platforms 